\title{
Shutterless deposition of phosphorous doped microcrystalline silicon by Cat-CVD
}

M. Fonrodona ${ }^{1}$, A. Gordijn ${ }^{2}$, M.K. van Veen ${ }^{2}$, C.H.M. van der Werf ${ }^{2}$, J. Bertomeu ${ }^{1}$, J. Andreu $^{1}$ and R.E.I. Schropp ${ }^{2}$

${ }^{1}$ Dept. Física Aplicada i Òptica, Universitat de Barcelona, Av. Diagonal 647, 08028 Barcelona, Spain

${ }^{2}$ Utrecht University, Debye Institute, SID - Physics of Devices, P.O. Box 80.000, 3508 TA Utrecht, The Netherlands

\begin{abstract}
In this paper we present results on phosphorous-doped $\mu \mathrm{c}-\mathrm{Si}: \mathrm{H}$ by catalytic chemical vapour deposition in a reactor which internal arrangement does not include a shutter. An incubation phase of around $20 \mathrm{~nm}$ seems to be the result of the uncontrolled conditions that take place during the first stages of deposition. The optimal deposition conditions found lead to a material with a dark conductivity of $12.8 \mathrm{~S} / \mathrm{cm}$, an activation energy of $0.026 \mathrm{eV}$ and a crystalline fraction of 0.86 . These values make the layers suitable to be implemented in solar cells.
\end{abstract}

\section{Keywords}

Microcrystalline silicon, Catalytic CVD, phosphorous doping 


\section{Introduction}

Recent results on microcrystalline silicon $(\mu \mathrm{c}-\mathrm{Si}: \mathrm{H})$ devices deposited by Catalytic Chemical Vapour Deposition (Cat-CVD), also called Hot-wire CVD (HWCVD), have reported state-ofthe-art performance [1]. Most of devices incorporating intrinsic active layers deposited by Cat-CVD use heavily doped layers deposited by plasma enhanced CVD (PECVD) [1-3]. Nevertheless, Cat-CVD's advantages with respect to PECVD (higher deposition rates, lack of ion bombardment, greater ability to produce atomic hydrogen) could result in an improvement in the performance of a completely hot-wire grown device.

In this work we have focused in the study and optimisation of shutterless grown microcrystalline n-type layers by Cat-CVD so they can be incorporated to solar cells. A shutter is commonly used to avoid deposition on the substrate during the first stages of the process, while deposition conditions have not stabilized. In the $n-i-p$ solar cell configuration, the interface between the stainless steel substrate and the n-type layer does not play a critical role in the device performance. We will show that phosphorous-doped layers can be deposited without the use of a shutter, which allows the use of a very simple deposition geometry for such layers.

\section{Experimental}

A hot-wire assembly has been implemented in one of the chambers of an ultra high vacuum multichamber system (PASTA). Figure 1 shows the schematic cross-section of the chamber where both HWCVD and PECVD layers can be deposited. The hot-wire assembly consists of two linear tantalum filaments $(0.3 \mathrm{~mm}$ diameter $)$ separated $4 \mathrm{~cm}$ and placed around $1.5 \mathrm{~cm}$ below the substrate. Due to its internal arrangement no shutter has been implemented in this 
chamber. In these shutterless conditions first the filament was heated to the deposition temperature, then the gas mixture $\left(\mathrm{H}_{2}, \mathrm{SiH}_{4}\right.$ and $\left.\mathrm{PH}_{3}\right)$ was added and, finally, the process pressure was set. Hydrogen flow of $100 \mathrm{sccm}$ and process pressure of $0.1 \mathrm{mbar}$ were used in all samples. Two different doping levels were used, $\left[\mathrm{PH}_{3}\right] /\left[\mathrm{SiH}_{4}\right]=0.48 \%$ and $0.92 \%$ in the gas phase. Filament temperature $\left(T_{f}\right)$ was $1850^{\circ} \mathrm{C}$ except in the $T_{f}$ series. No heater or any other heat source but the wires themselves were used to heat the samples during deposition. $\mu \mathrm{c}-\mathrm{Si}: \mathrm{H}$ films were deposited on $10 \mathrm{~cm}$ x $10 \mathrm{~cm}$ Corning 1737 glass. The thickness of the films was measured with a Dektak profilometer and with reflection/transmission measurements, from which we also obtained the refraction index $\left(\mathrm{n}_{0}\right)$. Raman spectra were taken with a Jobin-Yvon T64000 spectrometer illuminating both from the top of the sample and through the glass. From these spectra, crystalline fraction $\left(\mathrm{X}_{\mathrm{c}}\right)$ was calculated following [4]. Dark conductivity $\left(\sigma_{d}\right)$ and activation energy $\left(E_{a}\right)$ were obtained from conductivity vs. temperature measurements. Crystalline preferential orientation was deduced from X-Ray Diffraction.

\section{Results and discussion}

All samples exhibited a clear inhomogeneity in thickness, as can be seen in the thickness profile in figure 2 . This is caused by the difference between the filament-substrate distance $(1.5 \mathrm{~cm})$ and the distance between the two wires $(4 \mathrm{~cm})$. Material grown between the wires presented slightly higher dark conductivity and lower crystalline fraction values than that grown directly above the wires. On the other hand, material grown at the edge of the substrate had worse electrical and structural properties. This can be optimised in further experiments. Results presented in this paper refer, unless indicated otherwise, to material deposited right above the filament. 
Different starting procedures have been tried in order to minimise the effect of the lack of control of the technological parameters when the gases are introduced into the chamber. For that purposes, two films were deposited, being the only difference between them the sequence in which the different gases were introduced in the chamber. In one case after the wire had been set to the process temperature, all gases were introduced in the chamber at once whereas in the other film, silane was introduce in the chamber once hydrogen and phosphine flows had stabilized. Figure 3 presents the Raman spectra of these two samples. The first sequence resulted in a sample with $X_{c}=0.51$. On the contrary, the film grown following the second procedure was almost entirely amorphous. The difference could be attributed to the existence of a huge pressure peak in the latter the moment silane entered the chamber. One consequence of very high pressure is polymerisation. Initial deposition of large Si chains might decrease the number of nucleation centres and result in a more amorphous growth.

All other samples analysed in this paper have been deposited following the first deposition sequence described above.

Thickness dependence of the crystalline fraction has been studied in order to verify if the uncontrolled deposition conditions in the very first stages due to the lack of shutter in our system caused the growth of material with poor structural properties. 130,50 and $20 \mathrm{~nm}$ thick samples were deposited using $2.5 \mathrm{sccm} \mathrm{SiH}_{4}$ and a gas concentration of $\mathrm{PH}_{3}$ of $0.48 \%$. Figure 4 shows the evolution of the Raman spectra measured illuminating from the top of the sample with thickness. The $X_{c}$ values were 0.89 for the $130 \mathrm{~nm}$-thick layer and 0.70 for the $50 \mathrm{~nm}$ thick one. Crystalline fraction values obtained illuminating through the glass were around 0.67 in both cases. Crystalline preferential orientation in these films was (111). On the contrary, the thinnest layer was clearly amorphous from both sides. Electrical measurements performed on the $50 \mathrm{~nm}$-thick sample (thickness suitable to be used in n-i-p solar cells) 
resulted in $\sigma_{\mathrm{d}}=5.4 \mathrm{~S} / \mathrm{cm}$ and $\mathrm{E}_{\mathrm{a}}=0.034 \mathrm{eV}$. The same trend has been observed using different deposition conditions $\left(\mathrm{T}_{\mathrm{f}}=1950^{\circ} \mathrm{C}, 1.3 \mathrm{sccm} \mathrm{SiH} 4\right.$ and $\left.0.92 \% \mathrm{PH}_{3}\right)$. In this case a reduction in thickness caused a change in the electrical parameters from clearly microcrystalline electrical values at $50 \mathrm{~nm}\left(\sigma_{\mathrm{d}}=1.1 \mathrm{~S} / \mathrm{cm}, \mathrm{E}_{\mathrm{a}}=0.08 \mathrm{eV}\right)$ to ones characteristic for amorphous material at $27 \mathrm{~nm}\left(\sigma_{\mathrm{d}}=6.4 \times 10^{-3} \mathrm{~S} / \mathrm{cm}\right.$ and $\left.\mathrm{E}_{\mathrm{a}}=0.35 \mathrm{eV}\right)$. This behaviour seemed to indicate the existence of an incubation layer with a thickness around 20 $\mathrm{nm}$ as a consequence of the uncontrolled conditions in the chamber until gas flows are stabilized. Incubation phase thickness observed in samples grown using a shutter at similar deposition conditions, with very high hydrogen dilution, is of tens of $\AA[5,6]$.

Studies (not presented here) of hydrogen dilution and doping concentration have shown that an optimum compromise between electrical and structural properties and deposition rate is found using $1.3 \mathrm{sccm} \mathrm{SiH}_{4}$ (hydrogen dilution $\mathrm{D}_{\mathrm{H}}=\phi\left(\mathrm{H}_{2}\right) /\left[\phi\left(\mathrm{H}_{2}\right)+\phi\left(\mathrm{SiH}_{4}\right)\right]=98.7 \%$ ) and $0.92 \% \mathrm{PH}_{3}$ gas phase concentration at $\mathrm{T}_{\mathrm{f}}=1850^{\circ} \mathrm{C}$.

The following step to optimise the n-type $\mu \mathrm{c}-\mathrm{Si}: \mathrm{H}$ layers deposited without shutter was to study the effect of the Ta wire temperature in the above-mentioned conditions. With this purpose several samples around $50 \mathrm{~nm}$ thick were deposited in the range of $\mathrm{T}_{\mathrm{f}}$ comprised between 1580 and $1950^{\circ} \mathrm{C}$. Figure 5 shows the evolution of both dark conductivity and activation energy with $T_{f}$. $\sigma_{d}$ increased with increasing $T_{f}$ up to a value of $12.8 \mathrm{~S} / \mathrm{cm}$ at $1770^{\circ} \mathrm{C}$. For higher temperatures, $\sigma_{\mathrm{d}}$ decreased again to $\sigma_{\mathrm{d}}=1 \mathrm{~S} / \mathrm{cm}$ at $1950^{\circ} \mathrm{C}$. The activation energy presented a minimum at $\mathrm{T}_{\mathrm{f}}=1770^{\circ} \mathrm{C}\left(\mathrm{E}_{\mathrm{a}}=0.026 \mathrm{eV}\right)$ increasing then to $0.08 \mathrm{eV}$ at $1950^{\circ} \mathrm{C}$. Crystalline fraction values show little differences in the range of temperatures studied. The most crystalline sample is the one deposited at the highest $\mathrm{T}_{\mathrm{f}}\left(\mathrm{X}_{\mathrm{c}}=0.91\right)$ whereas the film that presented less crystalline contribution was the one deposited at $1770^{\circ} \mathrm{C}$ $\left(X_{c}=0.86\right)$. The refraction index calculated from the reflection/transmission measurements also has its maximum at the same $\mathrm{T}_{\mathrm{f}}$. This trend seemed to indicate that $\mu \mathrm{c}-\mathrm{Si}: \mathrm{H}$ grown 
around this wire temperature has a slightly bigger amount of amorphous phase (i.e., less crystalline fraction) but that the amorphous tissue is denser (maximum in the refraction index).

Phosphorous-doped $\mu \mathrm{c}-\mathrm{Si}: \mathrm{H}$ deposited under optimised conditions exhibited dark conductivity and activation energy values $(12.8 \mathrm{~S} / \mathrm{cm}$ and $0.026 \mathrm{eV}$ in $50 \mathrm{~nm}$-thick films grown at $1 \AA / s$ ) that make them suitable to be included in a solar cell. These features are comparable to those obtained in PECVD n-type layers $(24 \mathrm{~S} / \mathrm{cm}$ and $0.03 \mathrm{eV}$ in films grown at $0.08 \AA / s$ ) deposited in the same chamber.

\section{Conclusions}

A hot-wire assembly has been implemented in our reactor, allowing PECVD and HW deposition of thin silicon films in the same chamber. Due to its internal arrangement the deposition chamber is shutterless.

An incubation layer of around $20 \mathrm{~nm}$ might be the result of the uncontrolled conditions caused by the lack of shutter during the first stages of the deposition. The sequence in which gases are introduced in the chamber can cause changes in the film structure. Therefore, even though the presence of a shutter in the deposition chamber might be advisable to prevent the above-mentioned effects, it is demonstrated here that a shutter is not strictly necessary to obtain n-type nc-Si:H suitable to be implemented in solar cells. This result is of special interest when dealing with large area deposition systems, where a shutter can not be handled.

$50 \mathrm{~nm}$-thick n-type $\mu \mathrm{c}-\mathrm{Si}: \mathrm{H}$ with good electrical and structural proprieties has been obtained by properly tuning the deposition conditions. Best values obtained make this material suitable to be used in photovoltaic devices. Further studies include the utilisation of these films in solar cells. 


\section{Acknowledgements}

The part of the work carried out in the Universitat de Barcelona has been financed by the Spanish Government (MAT2001-3451-C03-01). The authors want to thank the Netherlands Agency for Energy and Environment (NOVEM). We also want to thank the ScientificTechnical Services of the UB for the Raman and XRD measurements. M. Fonrodona wants to thank Generalitat de Catalunya for financial support under grant 2001BEAI200159.

\section{References}

[1] S. Klein, F. Finger, R. Carius, B. Rech, L. Houben, M. Luysberg, M. Stutzman, MRS Proceedings 715 (2002).

[2] R. E. I. Schropp, Thin Solid Films 403-404 (2002) 17.

[3] C. Niikura, S.Y. Kim, B. Drévillon, Y. Poissant, P. Roca i Cabarrocas, J.E. Bourée, Thin Solid Films 395 (2001) 178.

[4] Z. Iqbal, S. Veprek, A.P. Webb, P. Capezzuto, Solid State Commun. 37 (1981) 993

[5] J.K. Rath, F.D. Tichelaar, H. Meiling, R.E.I. Schropp, MRS Proceedings 507 (1998) 879.

[6] M. Fonrodona, D. Soler, J.M. Asensi, J. Bertomeu, J. Andreu, J. Non-Cryst. Solids 299302 (2002) 14. 


\section{Figure captions}

Fig. 1. Schematic cross-section of the deposition chamber.

Fig. 2. Thickness profile of a $\mu \mathrm{c}-\mathrm{Si}: \mathrm{H}$ film. The numbers represent the relative thickness in $\%$.

Fig. 3. Raman spectra of samples deposited with different initial sequences.

Fig. 4. Evolution of Raman spectra with thickness.

Fig. 5. Dark conductivity $\left(\sigma_{d}\right)$ and activation energy $\left(E_{a}\right)$ as a function of the filament temperature. Lines are set as a guide for the eye. 
Figure 1

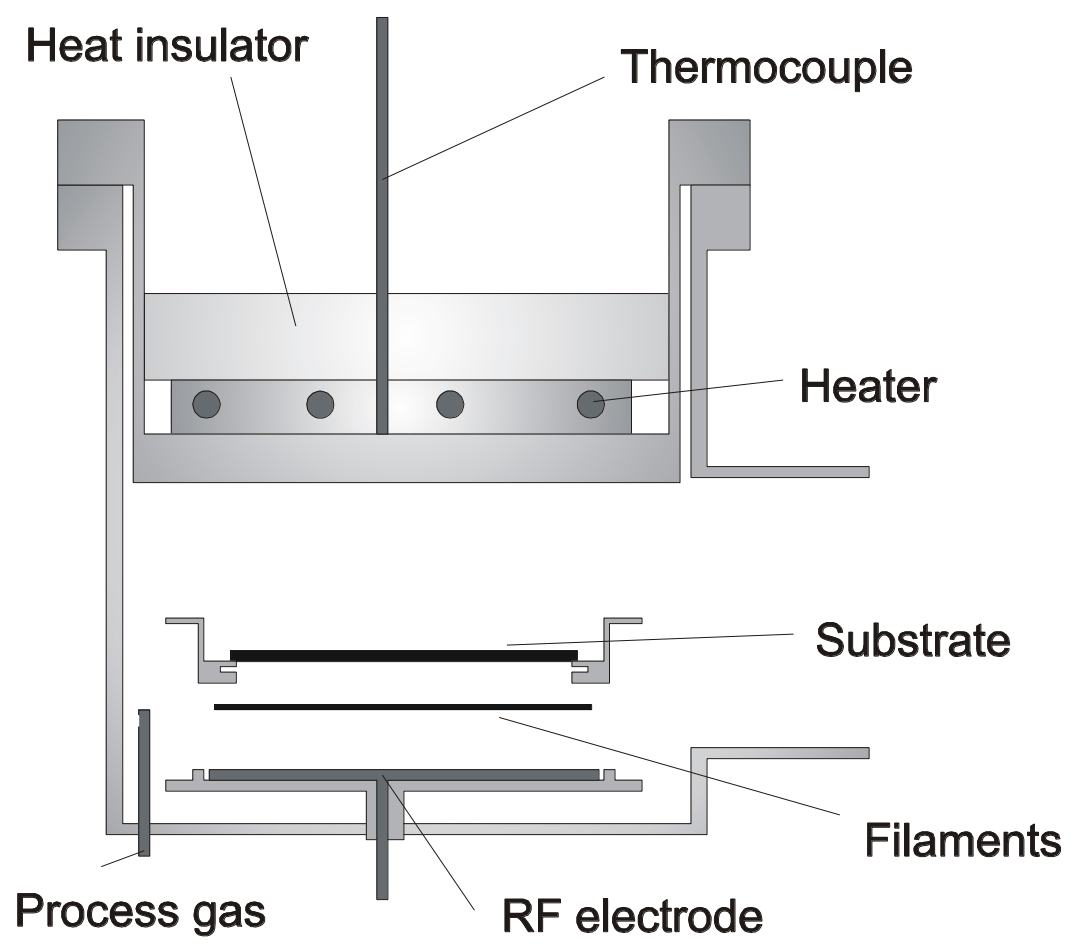


Figure 2

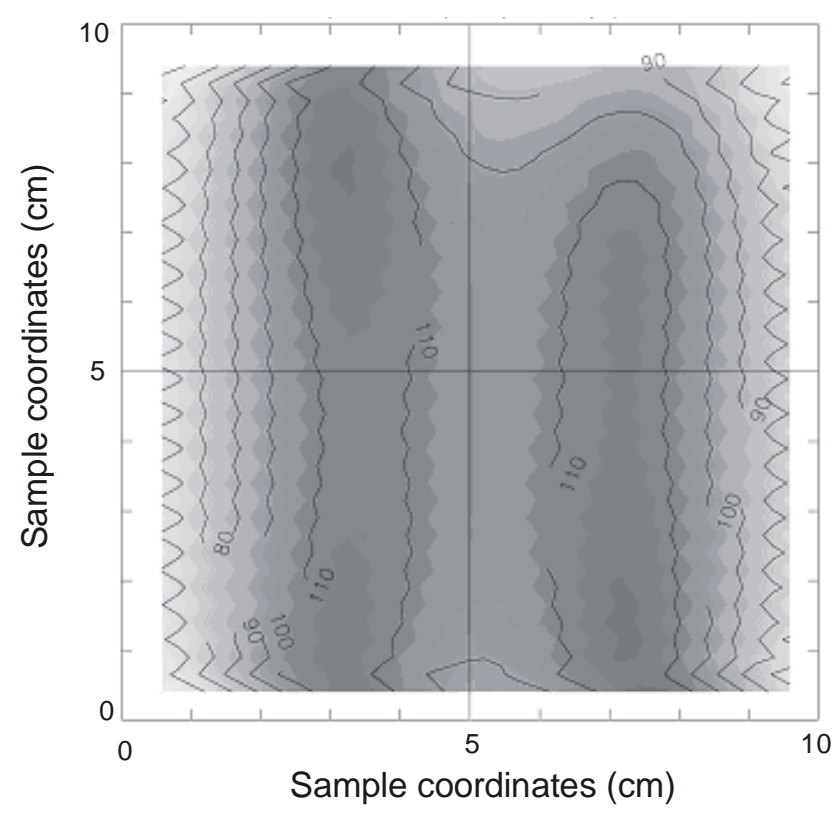


Figure 3

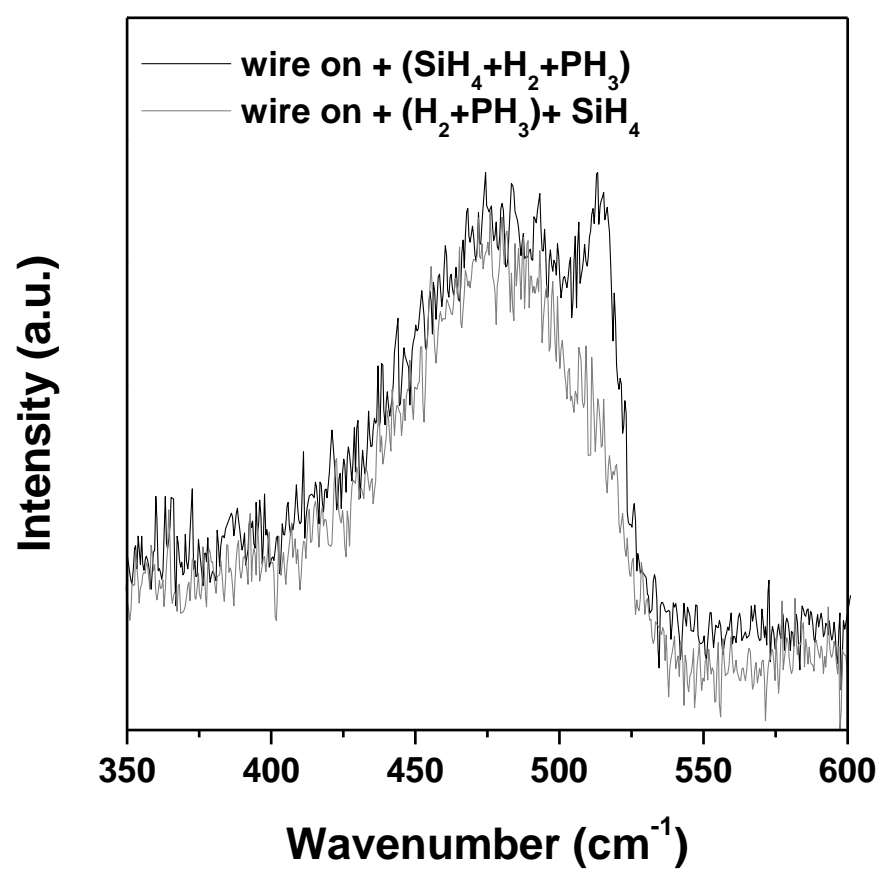


Figure 4

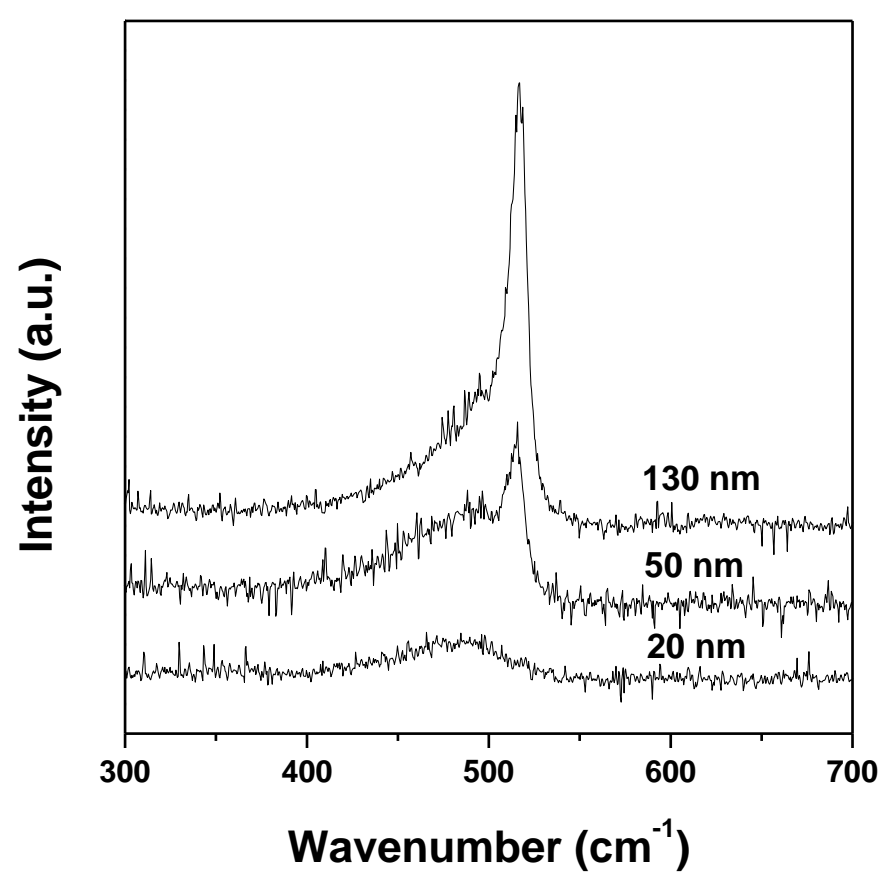


Figure 5

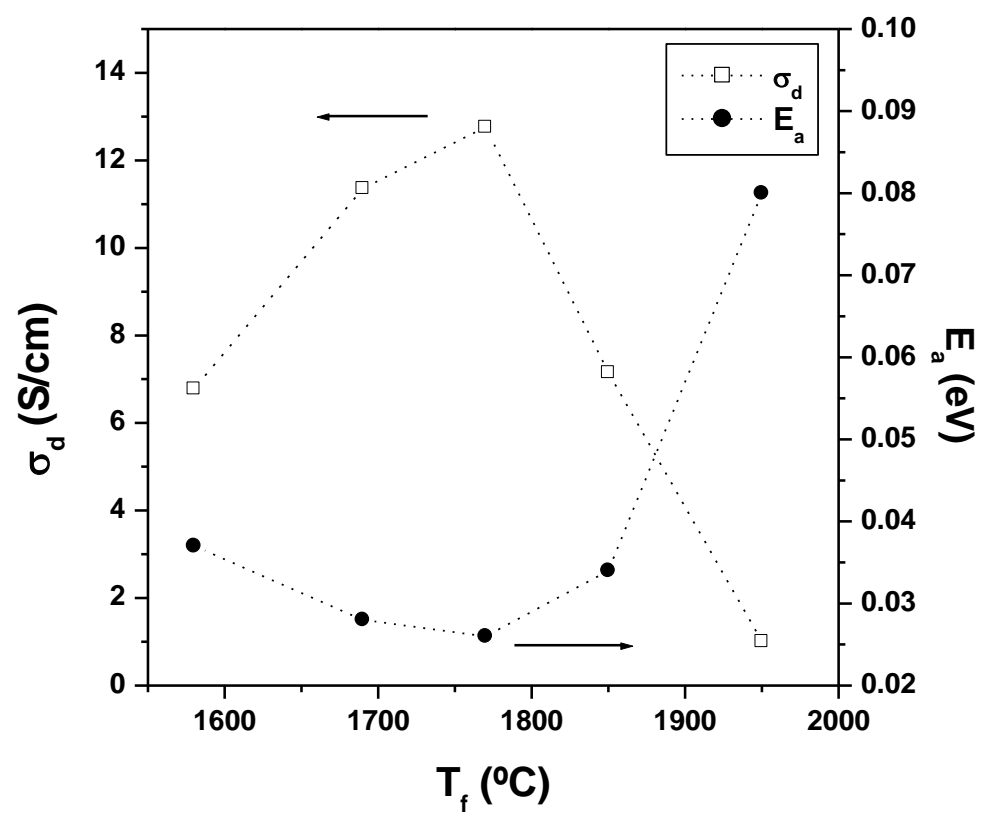

